\title{
Thermal Comfort Assessment of an Office Building in Tropical Climate Condition
}

\author{
Kelly Koh ${ }^{1}$, Hussain H. Al-Kayiem ${ }^{1, *}$, and Jundika C. Kurnia ${ }^{1}$ \\ ${ }^{1}$ Department of Mechanical Engineering, Universiti Teknologi PETRONAS, 32610 Bandar Seri \\ Iskandar, Malaysia
}

\begin{abstract}
As a lot of people spend their time indoor, indoor thermal comfort will affect the performance of the occupants in terms of health, comfort and productivity. This paper aims to investigate the thermal comfort of an office building constructed using low cost materials in tropical climate condition. That has been achieved by investigating the PMV using the CBE thermal comfort tool in the post-graduate office building in the solar research site in UTP. The experimental measurements have been conducted at two different cases; without ventilation and with air-conditioned in the office building. The thermal comfort of the office building is assessed by using the ASHRAE thermal sensation scale. Results have demonstrated that the office room without ventilation is hot and not suitable for occupants to work at such thermal environment. Thermal comfort of the room with airconditioning is warm and is slightly better than the room without ventilation as the PMV has been improved by around $60 \%$. However, the acceptable thermal comfort level in the low-cost material office building is yet to be achieved.
\end{abstract}

\section{Introduction}

The geographical location of Malaysia is at latitude $3.12^{\circ} \mathrm{N}$ and longitude $101.55^{\circ} \mathrm{E}$, thus Malaysia's climate is categorized as equatorial where it is hot and humid throughout the year. In addition to the alarming environmental problem - global warming, people spend approximately 80 percent of their time indoors [1-3]. The indoor building environment contributes to the performance of the occupants in terms or health, comfort, and productivity [3].

Indoor thermal comfort is dependent on the operation of heating, ventilation, and air conditioning (HVAC) [4]. The climate change affects the operation of HVAC by increasing the energy consumption in the building. The energy consumption of the building sector in developed countries is in between 20 percent to 40 percent [5-6]. In Malaysia, the energy consumption of the building is 15 percent and is expected to increase at about 6 percent per year. Buildings in tropical climate like Malaysia are constantly exposed to solar radiation throughout the year contributing to increase of cooling load of the building [7-8]. The buildings in Malaysia consumed 53 percent of electrical energy for air conditioning only to achieve thermal comfort [8]. In parallel to that, the number of research on thermal comfort is

\footnotetext{
* Corresponding author : hussain_kayiem@utp.edu.my
} 
increasing. The study of thermal comfort is important to provide satisfactory condition for occupants and control the energy consumption of the building [9].

According to American Society of Heating, Refrigerating, and Air-Conditioning (ASHRAE), thermal comfort is defined as "the condition of mind that expresses satisfaction with thermal environment and is assessed by subjective evaluation - ASHRAE 55" [10]. As Malaysia is experiencing tropical climate which is hot and humid throughout the year, the recommended indoor design temperature and relative humidity by ASHRAE 55 is not quite accurate. According to Department of Standards Malaysia (DOSM), the recommended indoor design temperature and relative humidity are $23^{\circ} \mathrm{C}$ to $26^{\circ} \mathrm{C}$ and $60 \%$ to $70 \%$ respectively [11].

Thermal comfort depends on the heat balance across the body and environment in an equilibrium state [12]. Predicted mean vote (PMV) is a thermal comfort model developed by Fanger to predict thermal sensation of occupants in an indoor environment by considering the heat balance between the actual heat flow from human body in given environment and heat flow required to achieve optimum comfort at a specified activity [11-13]. Predicted percentage dissatisfied (PPD) is the thermal comfort model developed by Fanger to predict the percentage of occupants who are dissatisfied with the room thermal comfort [4]. PMV is used to predict the sensation scale between cold to hot as shown in Table 1 below. The recommended acceptable PMV range for thermal comfort is between \pm 0.5 and PPD must be less than $10 \%$.

Table 1. Thermal sensation scale [10].

\begin{tabular}{|c|c|}
\hline Value & Sensation \\
\hline-3 & Cold \\
\hline-2 & Cool \\
\hline-1 & Slightly cool \\
\hline 0 & Neutral \\
\hline 1 & Slightly warm \\
\hline 2 & Hot \\
\hline 3 & \\
\hline
\end{tabular}

The aim of this paper is to present and discuss the thermal comfort and thermal sensation of an office building in tropical climate. This paper also presents the investigation results of experimental measurements of two different cases; no ventilation and air-conditioned room in terms of PMV and PPD.

\section{Methodology}

\subsection{Experimental model}

The research site (SRS) is in Universiti Teknologi PETRONAS (UTP) located at $4.3857^{\circ} \mathrm{N}$, $100.9793^{\circ} \mathrm{E}$. The weather of this region is mainly hot and humid with showers and occasional thunderstorm. The office building in the site constructed by using low cost materials including composite metal sheet for the exterior wall, gypsum board for the interior wall, and 
sandwich panel for the roof. Although these materials are relatively cheaper compared to other materials, they permit large heat transfer from outside to inside of the building and contribute to heat trapped in the building resulting in low thermal comfort in the building.

\subsection{Experimental setup}

The experimental measurement is conducted in the post-graduate office in the SRS. Figure 1 displays the position of thermocouples, globe thermometer and hygrometer in the room. The ambient temperature and solar irradiance measurements are conducted for 10 consecutive days. The experimental measurement is divided into two cases; without ventilation and with air-conditioning where the measurement for each case is conducted for 5 consecutive days.

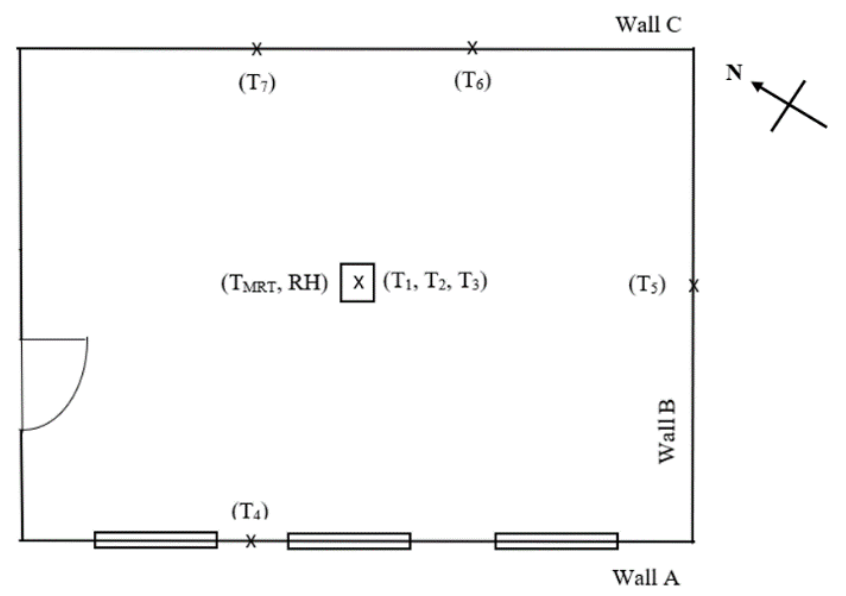

Fig 1. Layout of post graduate office building and position of measuring instruments.

All the measurements are conducted for 10 hours from 8:00 am to 6:00 pm. PMV and PPD is calculated using Center for Built Environment (CBE) thermal comfort tool [13]. The estimated values for certain parameters are shown in Table 2 below.

Table 2. Estimated value for clothing factor, clothing insulation, convection heat transfer coefficient, and metabolic rate.

\begin{tabular}{|l|l|l|l|}
\hline & \multicolumn{1}{|c|}{$\begin{array}{c}\text { Air Velocity } \\
(\mathrm{m} / \mathrm{s})\end{array}$} & $\begin{array}{c}\text { Metabolic } \\
\text { Rate } \\
(\mathrm{met})\end{array}$ & $\begin{array}{c}\text { Clothing } \\
\text { level } \\
(\mathrm{clo})\end{array}$ \\
\hline Estimated value based on ASHRAE & 0.1 & 1.1 & 0.5 \\
\hline
\end{tabular}

\section{Results and discussion}

The ambient temperature and solar irradiance measurements are conducted for 10 consecutive days from 8:00 am to 6:00 pm as shown in Figure 2 below. Solar irradiance is the distribution of solar radiation by the sun to the atmosphere. The intensity of the solar radiation varies depending on the latitude, atmospheric condition and time of the day. There are two types of solar radiation; direct radiation and indirect radiation. Although the peak temperature is at around 1 in the afternoon, the solar irradiance is not at maximum due to the heat trapped in the atmosphere. 


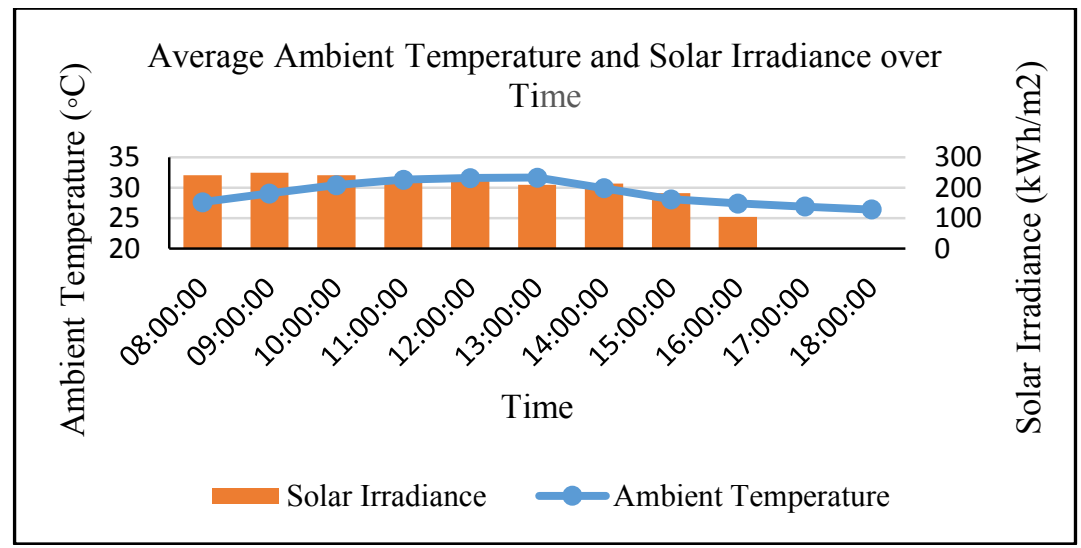

Fig 2. Average ambient temperature and solar irradiance over time for 10 consecutive days.

Figure 3 represents the calculated PMV from 8:00 am to 6:00 pm for 5 consecutive days for both cases, using $\mathrm{CBE}$ thermal comfort tool. According to ASHRAE thermal sensation scale, the acceptable PMV range is in between \pm 0.5 . The room without ventilation has a PMV index between 1 to 6 which explains that the room is too hot for occupants to work in. Although the room with air-conditioning has a lower PMV index between -1 to 3 with improvement at about 60 percent, the room is warm and is also not comfortable for the occupants to work in.

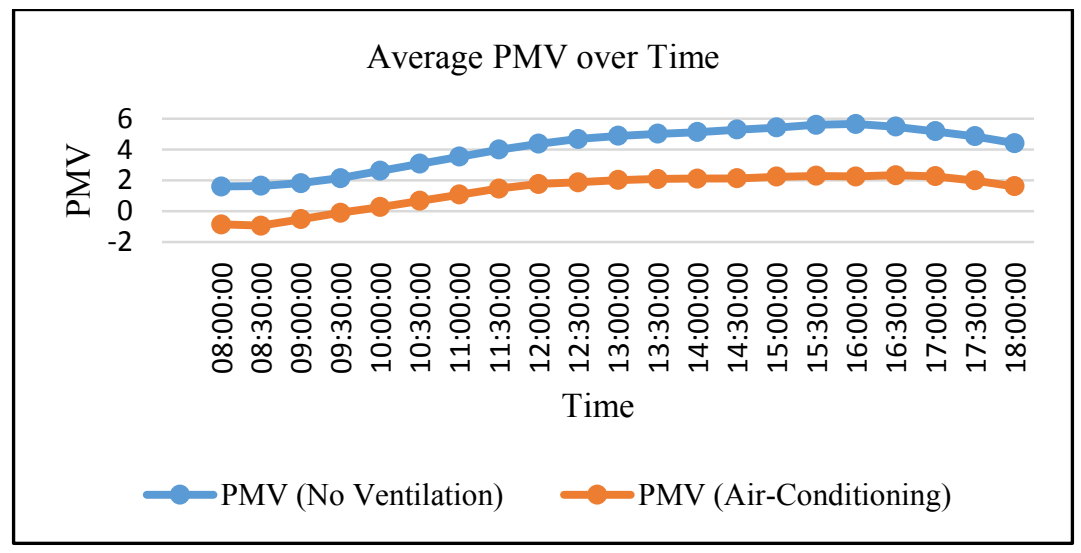

Fig 3. Average PMV over time for 5 consecutive days in room with no ventilation and room with airconditioning.

The PMV and PPD curve for both no ventilation room and air-conditioned room for average 5 days are shown in Figure 4 and Figure 5 respectively. In the no ventilation room, the thermal comfort of the room is very low. According to ASHRAE thermal sensation scale, the room is hot throughout the whole day and it has the range of 50 percent to 100 percent of dissatisfaction. The air-conditioned room also has a low thermal comfort level. According to ASHRAE thermal sensation scale, the room is slightly cool to neutral in the morning but slightly warm in the afternoon, but the room is warm until evening. 


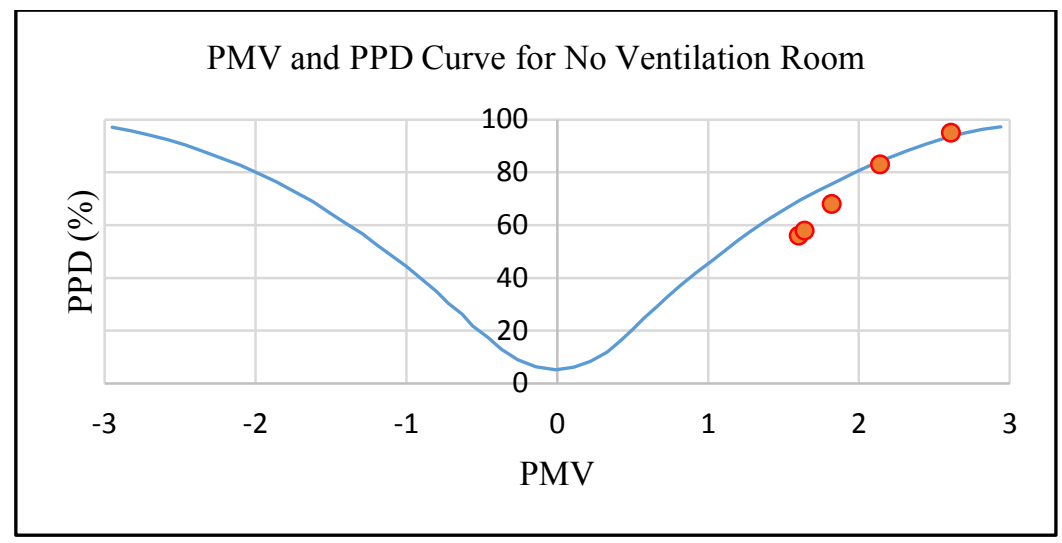

Fig 4. PMV and PPD curve for no ventilation room for average 5 days.

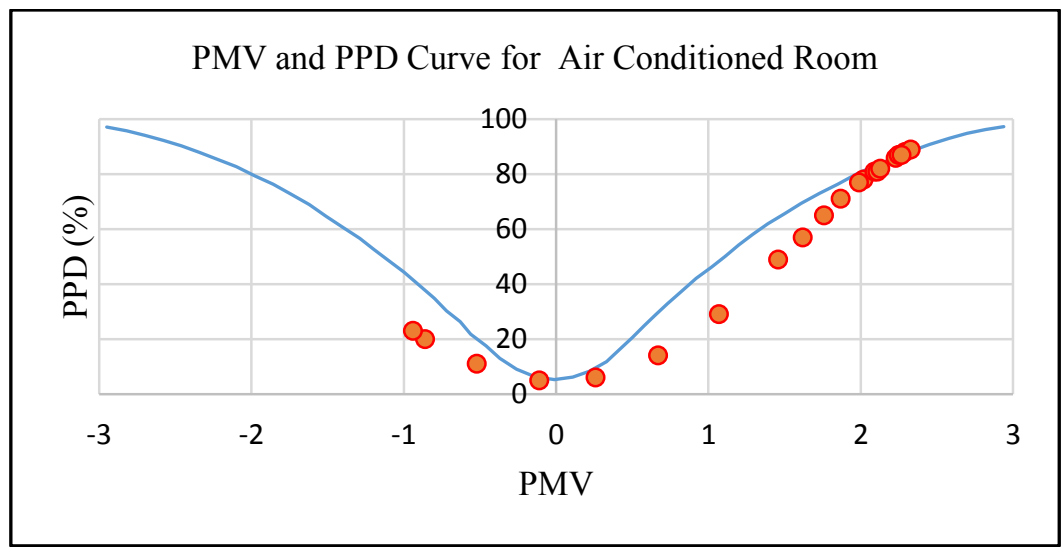

Fig 5. PMV and PPD curve for air-conditioned room for average 5 days.

Among other innovative technologies, greenery system is a great option to improve the thermal performance of the building. There are three classification of greenery system; green roof, green façade, and green wall. As the wall surface area has a higher fraction of the total building surface area, application of green façade or green wall not only can improve the thermal comfort of the office room but also reduce the internal wall temperature as it provides a layer of insulation to the external wall of the building contributing the lower exposure of solar radiation.

\section{Conclusion and recommendation}

In conclusion, the post-graduate office room under the existing conditions do not provide a comfortable thermal comfort environment for the occupants to work in. According to ASHRAE thermal sensation scale, the experimental measurements conducted concluded that the room is from the scale of 'warm' to 'hot'. Thus, it is recommended to use alternative methods such as green façade to achieve the optimum thermal comfort level so that occupants can work comfortably and efficiently.

The authors acknowledge Universiti Teknologi PETRONAS for the logistic support. Ministry of higher education in Malaysia (MOHE) is highly acknowledged for the financial support to purchase the 
required measuring tools used in the project and supported the publication of this paper under research grant [FRGS/1/2015/TK10/UTP/03/2] with CS:0153AB-K81.

\section{References}

1. B. Crook, N.C. Burton, Fungal Biol Rev, Indoor moulds, sick building syndrome and building related illness, 24, 106-113, (2010)

2. A. Norhidayah, C.K. Lee, M.K. Azhar, S. Nurulwahida, Procedia Eng, Indoor air quality and sick building syndrome in three selected buildings, 53, 93-98, (2013)

3. H. Wang, S. Hu, Build and Environ, Experimental study on thermal sensation of people in moderate activities, 100, 127-134, (2016)

4. D. Enescu, Renew Sust Energ Rev, A review of thermal comfort models and indicators for indoor environments, 79, 1353-1379, (2017)

5. R. Rupp, N.G. Vasquez, R. Lamberts, Energ and Buildings, A review of thermal comfort models in the built environment, 105, 178-205, (2015)

6. U. Berardi, Resour Conserv Recy, A cross-country comparison of the building energy consumptions and their trends, 12, 230-241, (2016)

7. Z. Gou, W. Gamage, S. Lau, S. Lau, Build, An investigation of thermal comfort and adaptive behaviors in naturally ventilated residential buildings in tropical climates: $A$ pilot study, 8, (2018)

8. P.H. Shaikh, N. Mohd, A.A. Sahito, P. Nallagownden, I. Elamvazuthi, M.S. Shaikh, Renew Sust Energ Rev, Building energy for sustainable development in Malaysia: A review, 75, 1392-1403, (2017)

9. M. Taleghani, M. Tenpierik, S. Kurvers, A. Dobbelsteen, Renew Sust Energ Rev, A review into thermal comfort in buildings, 26, 201-215, (2013)

10. ANSI/ASHRAE Standard 55, Thermal environment conditions for human occupancy, (2004)

11. Department of Standards Malaysia, Malaysian Standard, MS1525 Code of practice on energy efficiency and use of renewable energy for non-residential buildings, (2001)

12. N. Djongyang, R. Tchinda, D. Njomo, Renew Sust Energ Rev, Thermal comfort: A review paper, 14, 2626-2640, (2010)

13. T. Hoyt, S. Schiavon, A. Piccioli, T. Cheung, D. Moon, K. Steinfeld, CBE Thermal Comfort Tool. Center for the Built Environment, University of California Berkeley, http://comfort.cbe.berkeley.edu/, (2017) 